\title{
LA REVUELTA O MALÓN DEL “CACIQUE AGUSTÍN CURIÑANCU” A LA LUZ DE UN MEMORIAL DE 1765*
}

Eric Eduardo Palma G.**

Fecha de recepción: 3 de mayo de 2017

Fecha de evaluación: 23 de agosto de 2017

Fecha de aprobación: 29 de agosto de 2017

Artículo de reflexión

DOI: http://dx.doi.org/10.18359/prole.3327

Forma de citación: Palma, E. E. (2018). La revuelta o malón del "cacique Agustín Curiñancu" a la luz de un memorial de 1765. Revista Prolegómenos Derechos y Valores, 21, 41, 11-24. DOI: http://dx.doi.org/10.18359/prole.3327

\section{RESUMEN}

Se analiza en este trabajo el intento de reducir los indios chilenos a pueblos y la acción bélica del lonko Curiñancu (1766) como respuesta a dicha política. El artículo aporta nuevos antecedentes para la comprensión de dicho malón utilizando los Parlamentos hispano-indígenas y un memorial inédito escrito en 1765 y encontrado en el Archivo Histórico Nacional de Madrid ("Manifiesto que acredita las utilidades que se conseguirán en reducir los indios chilenos a vivir en población, los medios de conseguirlo y condiciones con que se ha de practicar").

\section{Palabras clave:}

Malón de 1766, lonko Curiñancu, reducciones indígenas, civilización de indígenas, evangelización, historiografía jurídica indiana.

" El presente artículo se desarrolló en el contexto del proyecto "Fondo de apoyo a la investigación en docencia de pregrado", de la Facultad de Derecho de la Universidad de Chile (Santiago de Chile, Chile).

** Abogado, magíster en Historia y doctor en Derecho. Profesor titular, cátedra de Historia del Derecho, Facultad de Derecho, Universidad de Chile (Santiago de Chile, Chile). Correo electrónico: epalmag@derecho.uchile.cl 


\title{
THE RIOT OR MALÓN OF THE CHIEF AGUSTIN CURIÑANCU UNDER THE LIGHT OF A 1765 MEMO
}

\author{
SUMMARY
}

The attempt to slash Chilean Indians to towns and the warlike action of Lonko Curiñancu (1766) as an answer to that policy are analyzed in this paper. This article provides new antecedents to the Malón comprehension by using both the Hispanic-indigenous parliaments and an unprecedented memo written on 1765, which was found in the National Historic Archive of Madrid "Declaration that states the profits that would be gotten by slashing the Chilean indigenous to live in community, the means to reach it and the conditions to be practiced".

\section{Keywords:}

Malón de 1766, lonko Curiñancu, indigenous reductions, indigenous civilization, evangelization, Indiana legal historiography.

\section{A REVOLTA OU MULTIDÃO DO CACIQUE AGUSTÍN CURIÑANCU À LUZ DE UM MEMORIAL DE 1765}

\section{RESUMO}

Neste trabalho é analisada a tentativa de reduzir os índios chilenos para povos e a ação de guerreira do lonko Curiñancu (1766) em resposta à referida política. $O$ artigo fornece novos antecedentes para a compreensão da multidão usando os Parlamentos hispânico-indígenas e um memorial inédito escrito em 1765 e encontrado no Arquivo Histórico Nacional de Madrid ("Manifesto que acredita os lucros que serão alcançados na redução dos índios chilenos para viver em população, os meios de obtenção e as condições com que se tem que praticar").

\section{Palavras chave:}

Multidão de 1766, lonko Curiñancu, reduções indígenas, civilização de indígenas, evangelização, historiografia jurídica indiana.

\section{Introducción}

El presente trabajo, recurriendo al método histórico-jurídico, analiza el intento de reducir los indios chilenos a pueblos y la acción bélica como respuesta a dicha acción del lonko Curiñancu (1766), consultando nuevas fuentes directas como son los Parlamentos celebrados entre la Corona y distintas parcialidades indígenas, y un memorial de $1765^{1}$.

1 Los autores que han abordado esta acción armada, según veremos, no han recurrido a estas fuentes para el conocimiento y comprensión del fenómeno.
El memorial se conserva en Madrid en el Archivo Histórico Nacional, sección Estado, legajo número 2844 , número 158 , lugar donde se consultó con la denominación "Manifiesto que acredita las utilidades que se conseguirán en reducir los indios chilenos a vivir en población, los medios de conseguirlo y condiciones con que se ha de practicar" $"$.

$2 \quad$ El análisis del memorial permite algunas explicaciones en lo relativo a la sociedad y las instituciones jurídicas indianas en el Chile del siglo XVIII, la obra aborda importantes temas: evangelización y civilización, naturaleza humana, libertad y policía cristiana y política internacional: 
Se trata de una fuente histórica no explorada ni utilizada hasta ahora por la historiografía nacional (jurídica y general), cuyo análisis permite enriquecer las explicaciones al uso sobre la propuesta de reducciones a pueblos de los indígenas chilenos y la respuesta armada del lonko Curiñancu ante tal intento, y que se complementa con los datos que los Parlamentos aportan respecto de esta materia.

En la primera parte del artículo exponemos una perspectiva sintética del fenómeno de la formación de pueblos de indios y del asentamiento indígena, procurando destacar los intereses de la Corona, de la Iglesia y de los vecinos españoles en la fundación de pueblos y el impacto de esta política en las formas tradicionales de asentamiento indígena. Seguidamente abordamos la cuestión en el Reino de Chile en el siglo XVIII, para dar noticia de un caso de resistencia indígena, cuyo protagonista principal fue el cacique Curiñancu, a la implementación de reducciones de indios. Revisamos la literatura histórica y antropológica que se ha ocupado del tema, complementando los análisis con dos fuentes históricas no empleadas hasta ahora (los Parlamentos hispano-indígenas del siglo XVIII y un memorial inédito de 1765 sobre reducciones). Todo lo cual permite profundizar en el conocimiento del fenómeno y presentar una nueva perspectiva sobre la resistencia armada del cacique Curiñancu y la responsabilidad de los jesuitas.

\section{A. República de indios (pueblos de indios)}

El fenómeno de la formación de pueblos de indios se vincula a la tesis de la teoría de los estatutos jurídicos propios, desarrollada por la Escuela Chilena de Historia del Derecho ${ }^{3}$, que propone

visita de potencias extranjeras a la zona de autonomía indígena, resistencia a la conquista, esclavitud indígena, protección real a las prerrogativas de los indios, límites territoriales y descripción de los indígenas.

En esta ocasión, nos centraremos principalmente en el aporte del memorial para el mejor conocimiento de la política de reducción a poblaciones, fenómeno que se identifica como causal del malón de Curiñancu de 1766.

3 Para el conocimiento de esta escuela, véase Dougnac (1994). una explicación sobre la situación jurídica de los indígenas en el Imperio español. Dice al respecto el profesor Dougnac (1994, p. 314):

La sociedad indiana estará constituida por dos repúblicas: la de españoles y de indios, a las que se irá agregando paulatinamente un nivel intermedio -el de los mestizos, cada vez más numerosos-complicándose todavía con la llegada de los africanos en calidad de esclavos [...] en Indias será la diversidad étnico-cultual la que prime. La Corona, atenta a esta realidad de gentes disímiles en su cultura y etnia, dará regulación diversa a esos grupos diversos.

Analiza el autor la institución de los pueblos de indios, explicando que ellos surgieron pues

[... ] se vio que el aislamiento en que vivían los naturales y su propensión a la dispersión impedían la prédica de la fe, razón por la cual se incentivó la reducción de los aborígenes a poblados (que por esto tomaron el nombre de reducciones) que permitiría, además, la aculturación del natural (Dougnac, 1994, p. 326).

Gussinyer i Alfonso (1994) afirma que las primeras experiencias de reducción a poblados tuvieron lugar en Las Antillas a propósito de la actuación de los Jerónimos.

Durston (1999) nos recuerda que Bartolomé de las Casas consiguió en 1542, que la Corona le permitiera el establecimiento en Guatemala de pueblos de indios separados de los españoles. Lo propio ocurrió en México por iniciativa del obispo de Michoacán, así como en otros sitios. También cabría considerar la experiencia jesuita en territorio de la provincia de Paraguay y la influencia de sus ideas en la formación de reducciones en el sur andino.

Todo lo cual redundó en la distinción entre república de españoles y república de indios (Levaggi, 2001), figura esta última de enorme utilidad en el proceso de evangelización y civilización de los 
naturales, y cuyo éxito dependía de la aceptación por parte de los indios de la soberanía española. De hecho, esta distinción supone poblaciones y poblamientos de indios pacificados, es decir, los que aceptaron la soberanía del monarca y su sumisión, normalmente luego de la lectura del requerimiento.

Reducirlos a poblaciones implicaba en todo caso respecto de ciertos indígenas una modificación más o menos profunda de sus formas de asentamiento.

\section{B. Del asentamiento indígena a los pueblos de indios}

Conviene recordar que datos actuales indican que al menos desde el 10.000 a. C. se reconoce presencia humana en la zona araucana, y que desde el 8000 a. C. se pueden identificar cazadores-recolectores y cierta movilidad entre la costa occidental y la región andina oriental (Falabella, Uribe, Sanhueza, Aldunate e Hidalgo, 2016). En cuanto a su conformación como unidades de población se ha sostenido que:

El ritual funerario, reiterado comunitariamente sobre un mismo lugar elegido y creado, toma cuerpo en la participación de códigos simbólicos compartidos, los cuales se evidencian en la alfarería y seguramente en otros materiales y prácticas sociales [...] son elaborados para ser vistos por comunidades pequeñas y bien congregadas [...].

Desde el 800 d. C., se evidenciarían disímiles niveles de heterogeneidad en las estructuras sociales de las poblaciones alfareras tempranas. Las poblaciones de Cautín transitarían hacia comunidades más amplias con la consecuente existencia de una mayor diversidad de roles y estrategias de control y toma de decisiones en contextos de múltiples jerarquías (heterarquía). La expresión de las sociedades filiadas al complejo Pitrén en la zona lacustre tendría lugar entre poblaciones o comunidades más reducidas, con estrategias más conservadoras en sus prácticas econó- micas [...] con una menor heterogeneidad social y consecuentemente con una mayor preeminencia de las dinámicas jerárquicas (Adán et al., 2016, pp. 425-426).

Existen antecedentes suficientes, como apuntan Adán et al. (2016), para argumentar que en el periodo inmediatamente anterior a la llegada de los españoles varias comunidades recurren a:

[...] estrategias apropiativas como productivas; maíces, ceramios, ranas, quinoas y una significativa explotación del recurso camélido [que] forman parte de la efectiva estrategia de subsistencia. Los conjuntos documentados en la Isla Mocha permiten plantear [que] aunque existe un aprovechamiento del mar es evidente un incremento de las actividades hortícolas y ganaderas (Adán et al., 2016, p. 430).

Los cronistas nos muestran que los españoles no estuvieron dispuestos a aceptar una distribución de la población indígena que implicara su presencia en zonas poco accesibles para su política civilizadora y evangelizadora:

En este valle de Arauco en 39 grados que viene a ser derechamente antípodas por dos costados de los manchegos de España y así rivalizan los indios en las fuerzas con los manchegos y el temple de la tierra es el mismo y los mantenimientos de mucha fortaleza. Toda la gente de indios que viven en estos valles que hemos dicho, $y$ en los demás desde Chillán hasta la ciudad de Chiloé, que son 120 leguas, habitan en las montañas sin tener pueblo formado sino en sus chácaras y sementeras y esta es la causa porque es esta tierra tan difícil de conquistar [...] (Ocaña, 1995, p. 37).

Es así como en 1622 y 1690, se resolvió eximir de tributos a los indios que residieran en poblaciones en la frontera.

La cuestión central sostenida en el memorial de 1765 , esto es, la fundación de pueblos de 
indios o la reducción de los indios a poblaciones, parece responder a una antigua preocupación española (Jara y Pinto, 1981; Salvat, 1987; Vega, 1999). En efecto, ya en 1593 se manifestaba en un Parlamento la disminución de los indios como efecto dañino de irse a vivir a los montes (Zavala, 2015) .

Como anota Contreras (2016) la historia de la población indígena de los pueblos de indios, muestra un abandono paulatino y la inserción de los pobladores como trabajadores libres en las estancias del valle central. Whipple Morán afirma (1998):

Para los indios de encomienda, estos cambios sobre los medios de producción significaron el masivo traslado de ellos desde sus pueblos a las estancias de sus encomenderos, debido a la necesidad de contar en forma permanente con la mano de obra en el lugar donde se realizaban las labores agrícola-ganaderas (p. 364).

La política de fundación de poblaciones fue particularmente relevante en Chile en la segunda mitad del siglo XVIII de la mano de la dinastía borbónica (Lorenzo, 2004). Casanova Guarda (1987) aborda dicha política en relación con la rebelión de 1766, para concluir que la idea de poblar, ya sea con villas de españoles o de indios, era de antigua data. Cabe considerar que ya en el Parlamento de Tapihue de 1738, se propuso congregar a los indios para que vivieran en pueblos,

[...] como lo están los de la Mocha, San Christobal, Talcamavida, Santa Juana, Sante Fee, cuyo fruto ha sido que vivan como vasallos del Rey y ponerlos en lo que como legítimos vasallos de Vuestra Magestad deben observar y guardar, sacandolos de Ynfieles

$4 \quad$ Para el texto de los Parlamentos que se citan aquí se usa esta edición de Zavala, por lo que en adelante cada vez que se recurra a un Parlamento solo se citará el nombre del Parlamento y la página respectiva de la obra.

Se ha respetado la ortografía original de los textos históricos citados. esclavos del Demonio, a fieles hijos de Dios (Parlamento Tapihue, 1738, p. 237).

En dicho Parlamento de 1738 se proponía expresamente dejar de capitular con los indios por ser contrario al honor de las armas españolas y ser vasallos de la Corona, y como sustituto de lo que se juzgaba una errada práctica, "reducirlos a pueblos, y a que vivan en Politica Christiana, como los de las reducciones amigas" (Parlamento Tapihue, 1738, p. 238). Se desprende con claridad de la declaración, el deseo de la autoridad política del Reino de Chile de aplicar las reducciones a parcialidades indígenas cuya sumisión era a lo menos dudosa e inestable.

Jorge Pinto (1986) en su estudio sobre la obra de Joseph de Salas relativa a la visita de Espiñeyra, asegura que la fórmula de reducciones fue defendida por los sacerdotes jesuitas en oposición a los franciscanos, quienes eran partidarios de la fundación de escuelas donde se educara a los hijos de los caciques. Idea que desarrolla Goicovich (2007). Rosati Aguerre (1996) y Svriz (2011) dan cuenta de la experiencia jesuita en el río Uruguay en relación con la comunidad de los guenoas, parte de cuya población fue "reducida", lo que permitió contar con líderes indígenas que atrajeran a los demás "infieles" para la suscripción de un tratado de paz en 1732.

Una idea semejante apareció a propósito del problema chichimeca (1596), en que se sugirió que se formaran poblados con indios para que los rebeldes constataran las ventajas del asentamiento y convivencia con los españoles (De la Torre, 1992).

\section{La reducción de indios a pueblos y el malón de Curiñancu de 1766}

La literatura (Villalobos, 1995) entiende la acción bélica del lonko Curiñancu como una respuesta violenta de los indígenas a la propuesta de reducciones. Tal movimiento bélico se describe como levantamiento general de 1766 y una reacción a la política de fundaciones. Pinto (1986) señala respecto de esta revuelta: 
Los orígenes de esta estuvieron en la proposición que hicieron los jesuitas al gobernador Guill y Gonzaga de reunir a los mapuches en pueblos. Los padres de la Compañía pensaban, muy ingenuamente, que bastaba aquello para evangelizar y civilizar a los infieles [...] pusieron manos a la obra, fundando una serie de pueblos que de tales tenía apenas el nombre (p. 31).

Una versión semejante se encuentra en Correa y Mella (2009):

No obstante todos los esfuerzos desplegados, el 25 de diciembre de 1766 se produce un importante levantamiento indígena, conocido como el Malón de Curiñanco, en el que se abalanzan en forma simultánea un gran número de mapuche sobre las villas levantadas o en construcción, quemando las casas y destruyendo las iglesias de las misiones, y fruto de lo cual los habitantes de los pueblos destruidos, como de las haciendas, hubieron de ponerse a salvo arrancando al norte del Bio Bio.

Hablamos de una rebelión generalizada, si bien limitada en el tiempo, y que llegó a su fin en la medida que la intención de fundar pueblos quedó sólo en eso, en intención.

Para León (1990) el proyecto de fundar poblaciones:

[...] no era nuevo y se insertaba adecuadamente en la política fundacional auspiciada por la Corona Borbona. De acuerdo a esta política se debía agrupar a la población rural para facilitar la colección de tributos, fiscalizar las transacciones comerciales, regularizar el proceso de formación de la propiedad territorial y "racionalizar" la vida cotidiana del campesinado [...].

Hace responsable a los jesuitas de la iniciativa de las reducciones:

Aprovechando el recuerdo de la notable ocasión en que las ambiciones fundacio- nales desatadas por los jesuitas y el ejército de la frontera llevó a un serio quiebre de las relaciones fronterizas, los jefes llanistas manifestaron una vez más su descontento con el desempeño del antiguo maestre de campo Salvador Cabrito (León, 1996).

Zavala Cepeda (2008) quien realiza un análisis en profundidad del conflicto y cubre también los sucesos bélicos de 1769, llega a la conclusión que involucró a indígenas rebeldes con españoles e indígenas amigos de los españoles, representados por los caciques gobernadores, que facilitaron la fundación de pueblos, línea explicativa que estudia León en 1990.

La explicación sobre la responsabilidad de los jesuitas en los sucesos y la calificación de su propuesta como irreflexiva, están muy difundidas. Así Bonilla (1988) apunta que:

Guill y Gonzaga convocó a un Parlamento en Nacimiento el 8 de diciembre de 1764, para proponer a los naturales, aconsejado por un grupo de jesuitas jóvenes que desconocían la idiosincrasia mapuche, construir pueblos en que estos deberían vivir definitivamente, favoreciendo de esta manera la evangelización (pp. 195-196).

Lo propio sustenta Ferrando Keun (2012) aunque con una variante, pues agrega que la propuesta contaba con el beneplácito del rey. Dice al respecto, que el gobernador:

[...] inspirado por los misioneros jesuitas más jóvenes, se convenció que una buena solución para la pacificación, conquista y dominación de Arauco, era lo que proponían y que, además, coincidía con la opinión del Rey. Consistía esta innovación en obligar a los mapuches a vivir en poblados o agrupaciones, donde la acción misionera y evangélica podía ser constante, continuada y en ningún caso esporádica (p. 325).

Por su parte Casanova (1987) señala que existían dos perspectivas en el seno de los jesuitas, siendo los jóvenes los partidarios de las reducciones. 


\section{La propuesta de reducciones de 1765}

Ninguna de estas explicaciones se construye recurriendo al manuscrito de 1765 . No se ha acudido al Memorial para explicar la iniciativa, contribución que esta publicación espera realizar. Pinto (1988) recuerda que en 1752 el jesuita Joaquín de Villarreal sostuvo la conveniencia de estas fundaciones de pueblos, lo que se reiteró en 1758:

Las ideas de Villarreal convencieron a los jesuitas que era conveniente ampliar la fundación de poblados al territorio de los mapuches, seguros de que era el mejor camino para lograr la conversión de los infieles y la pacificación de la frontera [...] Los jefes del ejército se inclinaron por los jesuitas, pues con ellos se justificaban. El proyecto inicial del padre Villarreal sugería, incluso, fundar los primeros pueblos entre los mapuches, bajo la protección de las tropas de la frontera. La fundación de pueblos convenía, pues, a unos y a otros ${ }^{5}$ (Pinto, 1988, pp. 32 y 43).

Cabe recordar que según lo establecido por Alcamán (1997) en este año el lonko Huarán de los llanos de río Bueno ofreció al gobernador de Valdivia, a cambio de apoyo militar contra las incursiones de los juncos, facilitar la formación de poblaciones y aceptar misioneros entre ellos.

En fecha mucho más cercana, 1765, el autor del manuscrito "Manifiesto que acredita las utilidades que se conseguirán en reducir los indios chilenos a vivir en población, los medios de conseguirlo y condiciones con que se ha de practicar" procuró demostrar las "muchas utilidades que se consiguieran, reduciéndose los indios chilenos a vivir juntos en villas" 6 .

5 El trabajo de Villarreal "Informe hecho al Rey nuestro Señor don Fernando el VI por Joaquín de Villarreal, sobre contener y reducir a la debida obediencia a los indios del Reino de Chile" tiene su versión en línea en http://www.memoriachilena.cl/602/w3-article-68735. html

6 El autor del memorial utiliza como términos sinónimos ciudades, villas, lugares, misiones y pueblos.
El autor realizó un contrapunto entre civilización y barbarie, arguyendo que aquellos que viven dispersos por campos y selvas "más parecen bestias, que hombres" y que las naciones que huyen de la sociedad son "las más bárbaras, impolíticas inhumanas".

No dudó en poner a los "árabes" como ejemplo de nación bárbara, impolítica e inhumana, no por razón de religión, sino por no vivir en ciudades o villas: "todas las naciones en que resplandece la luz de la razón aun siendo de diversa religión [...] han convenido en vivir en ciudades villas y lugares".

Del texto se desprende que la ciudad trae consigo un arreglo de la convivencia, entendido como el modo más racional de constituir la vida: la organización citadina permite a la autoridad implementar sus decisiones; disminuye el costo de ejecución de las mismas; favorece un fluido contacto entre el capital y el trabajo; facilita la administración del tiempo de las personas en función de los intereses reales; ampara a los indios de los malos tratos de los españoles; posibilita la convivencia entre indios y un número acotado e ideal de sacerdotes, garantizando un uso eficiente de los recursos de la Corona y del tiempo dedicado a la formación moral y religiosa de los indígenas; y asegura el acceso a la mano de obra.

La propuesta busca enfrentar los problemas que se suscitaban en un reino en que los indios "viven dispersos por centenares de leguas" y por ende sin control español. Del análisis del manuscrito surgen los antecedentes que hacían razonable la propuesta a ojos de las autoridades españolas y los religiosos:

1. "La mayor facilidad que tuvieran los misioneros de civilizar y reducir a la fe, y buenas costumbres a los Indios", implicará generar con pocos sacerdotes abundantes frutos.

2. La adopción de la fe por los indios los transformará en aliados de los españoles, como lo demuestran los guaraníes. 
3. La alianza con los indios hará dificultosa la penetración inglesa por la "diversidad de sectas y religión":

No ignoran los Indios de Chile que los ingleses sean herejes, y los misioneros con aquellas mismas luces, con que los persuaden que abracen la fe católica les infunden horror a toda herejía, y a los que la profesan. Si de esto se juntase, que viviendo en Pueblos, bajo las suaves leyes de nuestros monarcas libres de toda esclavitud y opresión gozasen de todos aquellos bienes que trae consigo la sociedad y estuviesen ciertos de que habrían de ser amparados, y protegidos en la posesión de sus haciendas y bienes por el Rey de España contra todos sus enemigos, no menos que los españoles, no se puede dudar que unirían sus fuerzas con las de los españoles contra los ingleses, a quienes miraran como enemigos de su patria, de su religión y de su Rey [...].

[Y para ello] el medio más fácil y más eficaz es el de reducir los indios a que vivan juntos en villas, con lo cual se evitaría aquel peligro, y se pusiera el Reyno en estado de seguridad, contra todos los esfuerzos de los ingleses.

4. El ahorro al erario de las dos terceras partes del dinero con que se mantiene a los misioneros y el empleo de esos recursos en llevar la palabra a los indios del Estrecho de Magallanes.

5. El menor desgaste en salud de los misioneros porque ya no necesitarán seguir a los indios a través de montes y selvas para darles adoctrinamiento.

6. El cambio de sus hábitos para hacerse más productivos:

Estando ya reducidos a la fe y vida civil en villas y lugares no vivieran con aquella desidia e inacción con que ahora pasan la vida, sino que se aplicaran al cultivo de sus tierras y al ejercicio de artes mecánicas y así con el de- curso del tiempo tendrían con que mantener a sus curas [...] -se aumentará- el número de gente empleada en cultivo de las tierras, trabajos de minas y otras manufacturas.

7. Viviendo en villas se podría ampliar la percepción de impuestos en favor de la Corona, que recibiría los tributos de entre

[...] veinte a treinta mil indios de armas en solo el terreno que se incluye entre el río Bío Bío y río Bueno, quedando como queda hasta el Estrecho de Magallanes dos tantos más de terreno poseído enteramente de indios bárbaros, sin incluir en esto las muchas islas que están cerca de la costa hasta el mismo Estrecho.

8. La reducción a villas permitiría a los pueblos (como ocurría, dice el autor, con los indios guaraníes y chiquitos) espantar la esclavitud y la opresión que "pudieren temer por parte de los españoles" y servir de ejemplo para los demás que verían la tranquilidad con que se goza de comodidades y bienes.

9. De lo cual se derivaría "un aumento de los indios muy considerable".

10. La fe provoca en los indios un alejamiento de la poligamia. Esta práctica, dice el memorialista, incide en la baja población de indios porque las mujeres menos favorecidas

[...] para desahogar sus celos y sentimientos se suspenden y ahorcan con grandísima facilidad valiéndose para esto de aquella misma faja con que se ciñen, siendo estos así cuantos menos indios nacerán de los que nacieran si dejada la poligamia se quitase la ocasión de los suicidios.

11. También ayudaría a asegurar que la intervención de potencias extranjeras en las costas del sur de Chile (inglesas y otras potencias europeas dice el autor) no se constituya en una amenaza para el mantenimiento del virreinato del Perú y del mismo México bajo dominio español. 
12. Si se llegasen a perder dichos virreinatos se produciría además un significativo daño económico, pues el mismo Reino de Chile, señala, es rico en minas de plata, oro y azogue, en madera, en azufre y salitre, en animales y cereales. Parte de esa riqueza no se puede explotar, pues está en poder de los indios que controlan el territorio.

13. La formación de villas y ciudades, dice el autor anónimo, hace más fácil la conquista de un pueblo como ha quedado demostrado en la conquista de Perú y de México. Ello porque:

[...] si vivieran juntos en villas era preciso que tuvieran en ellas bienes muebles, y raíces, arboledas y sementeras, para defenderlas no bastaba su caballería, como está claro; pues aun las ciudades más fuertes y muradas no se pueden defender con sola caballería, sin armas de fuego; pudieran evitar en su ruina con la fuga; pero no pudieran evitar la pérdida de todos los bienes que tuvieran en las villas, y así el amor de estos, y el temor de perderlos los contuviera en la debida sujeción.

El memorial afirma que en 1765 los indios "con juramentos han prometido que se reducirán a vivir juntos en pueblos". Y propone entonces un conjunto de acciones para llevar a cabo la fundación de "pueblos de indios":

a) que se vendan 4 títulos de Castilla para reunir fondos para las fundaciones;

b) que cada pueblo quede bajo protección de un oidor de la Real Audiencia;

c) que los caciques sean gobernadores perpetuos en sus respectivos pueblos y se elijan de entre los indios alcaldes cadañeros;

d) que los españoles no puedan sacar indios de los pueblos para su servicio y sea cargo en el juicio de residencia si jueces y corregidores no ordenan su restitución al pueblo respectivo; e) que se les entreguen tierras a los pobladores y a los caciques en triplicado para que provean a su condición;

f) que no gobiernen inmediatamente los españoles estos pueblos y tampoco comercien, ni permanezcan más de tres días entre ellos;

g) que para facilitar el comercio y evitar sus graves inconvenientes cuando los indios venden sus productos, se hagan cuatro ferias en el año en distintas zonas ${ }^{7}$;

h) que los precios sean supervisados por las autoridades indígenas y españolas, así como los bienes que reciben los indios;

i) que los indios honren la paz celebrada con el Marqués de Baides en $1640^{8}$ y colaboren con los españoles contra sus enemigos, debiendo entregarse para ello a los pueblos un terreno donde pasten los caballos;

j) que al toqui general se le dé sueldo perpetuo;

k) que el Rey de España les prometa defenderlos ante ataques de sus enemigos;

1) que no se funden pueblos de indios en las costas para que los españoles puedan instalar fortificaciones; y finalmente, que se observen las reglas velando por ello el Obispo de Concepción y los curas quienes pueden preguntar si ha habido violaciones, y si el Gobernador no ha hecho la denuncia pertinente, hacer ellos la denuncia a la Corte.

$7 \quad$ Ya en el Parlamento de Negrete de 1726 hubo reglas al respecto, elevando la aplicación de las buenas prácticas en el comercio a asunto de interés público, por el efecto negativo que provocaban en los indígenas los abusos de los españoles, mestizos, mulatos e incluso negros que comerciaban ilegalmente con ellos.

8 La fecha puede entenderse porque los preparativos empezaron en octubre de 1640 y la reunión de vecinos españoles se convocó para el 15 de diciembre del mismo año. Iniciándose el Parlamento el 6 de enero de 1641 (véase Szászdi y Palma, 1998). 
La fórmula de implementación pone de relieve que el memorialista tiene una cierta desconfianza del buen comportamiento y la buena fe de los vecinos. El artículo de Alcamán (1997) destaca el interés que los mapuches pudieron tener en el éxito de esta política en la medida que se ejecutara lo propuesto en las letras c), e), g), h), j) y k) de la cita anterior. Todo lo cual vendría a impactar en el mantenimiento y proyección de ciertos caciques (lonkos) y sus comunidades, amenazados por enemigos indígenas aledaños y por las dificultades socioeconómicas por las que atravesaban.

El Parlamento de Nacimiento de 1764, según el relato de Antonio Guill y Gonzaga, se refiere a las "diligencias practicadas en el importante asunto de reducir a Pueblos por ahora, y después al Christianismo" a los "Yndios barbaros habitantes de los Llanos que median entre esta Ciudad y, Valdivia" (Parlamento de Nacimiento, 1764, p. 273) a quienes se les propuso por primer artículo del Parlamento:

[...] el de reducirse a Pueblos en el Paraxe que quisiesen, $y$ en el numero de familias que tuviesen por combeniente para cada uno, esforzándoles razones de utilidad, que les resultarían de vivir como Racionales, con seguridad en sus Casas, Familias, Haciendas, y Muebles, libres de las Guerras, con que unos a otros se destruían, respecto a que Vuestra Magestad mandaba se les conservase sus tierras y derechos [...] y que si para mas felicidad suia quiciesen Misioneros, y Capitanes Españoles de conducta para que los governasen, se los mandaria dar luego (Parlamento de Nacimiento, 1764, p. 276).

Los caciques que concurrieron al Parlamento no aceptaron de buenas a primeras la idea del asentamiento:

[...] para prueva de la verdad con que procedían reservavan el dar respuesta absoluta sobre la reduccion a Pueblos (a que todos los presentes estaban promptos) hasta que tratándolo con los demas que no habían asistido, prestasen su consetimiento, y no ofreciese motivo de duda, a cuio fin me pidieron que asistiesen a sus juntas particulares algunos Capitanes españoles de confianza [...] quedandose muchos de los primeros Gobernadores y Caciques que lo solicitaron para tratar conmigo sobre el asumpto, y los medios que discurrian para consecución del fin de reducirse a Pueblos (Parlamento de Nacimiento, 1764, p. 276).

Guill y Gonzaga da noticia a la Corona de que de las juntas particulares resultó que los caciques y gobernadores de Angol, Nigninco, Minas, Lucan, Cullin, Repocura y Maquegua estaban prontos a reducirse a pueblos en cumplimiento del Parlamento "pidiendo algunos Capitanes Españoles que les he dado desde luego para que los gobiernen" (Parlamento de Nacimiento, 1764, p. 276). Sin embargo, hubo resistencia en la junta de Angol:

[...] tubo el atrevimiento el Cacique don Agustin Curiñancu y su Capitanejo Ygnacio [...] de oponerse a la Reduccion a Pueblos diciendo que ni en esto ni en otra cosa habían de obedecer al Capitan General, y conciderando que semejante exemplar pudiera acarrear fatales consequencias y desvaratar de un todo lo hasta aquí conseguido, me pareció haber llegado el caso de usar en medio de ellos de la Soberana Authoridad de Vuestra Majestad, y despues de bien refleccionado, embié con la preocupación correspondientes a traer presos a estos dos sediciosos (Parlamento de Nacimiento, 1764, p. 276).

Así se hizo y se les engrilló y condenó a uno a muerte y al otro a destierro perpetuo en la isla de Juan Fernández, para luego perdonarlos. Lo que motivó, según relato español, que se comprometieran con la política de reducciones.

Lo narrado por Guill y Gonzaga corresponde a sucesos acontecidos entre los meses de diciembre de 1764 y febrero de 1765 (la representación está fechada el 1 de marzo de 1765). El alzamiento 
de Curiñancu tuvo lugar a fines de diciembre de 1766.

Conviene precisar que lo ejecutado por los españoles fue visto también por los indios como un intento de refundar poblados hispanos:

Cabrito fue enviado a repoblar Angol, Francisco Ribera a fundar Mininco y Joaquín Burloa a Huequén [...] lo que equivalía a una invasión disimulada de Araucanía. El 25 de diciembre los llaneros, al mando del "toqui" Curiñancu, atacaron las diversas obras en construcción y las incendiaron. Así rompieron la paz iniciada en 1725 (Bonilla, 1998, p. 196).

Así las cosas, cabe concluir que la propuesta de reducciones contaba con el aval del gobernador; con el interés de ciertas parcialidades indígenas en la medida en que reconocía su autoridad y les garantizaba el comercio, ingresos permanentes y otras ventajas; así como con el respaldo del autor del manuscrito, que presumiblemente representaba los intereses de los sacerdotes. Sin embargo, el error del gobernador de apresar a Curiñancu, quien presentó, entre los convocados, una posición minoritaria de resistencia, desencadenó un alzamiento que echó por tierra una política que tuvo un inicio prometedor en tanto que fue aceptada a discusión por algunos líderes indígenas.

Años más tarde, en 1771 en el Parlamento de Negrete, la Corona debió declarar que no era su intención "alterar el modo en que han vivido y viven los Yndios poseyendo cada uno sus Tierras con independencia de otros sin precisarlos a que se reunan, y congreguen en Pueblos por los incombenientes que repetidas vezes me han representado". Recoge el relato la intervención del cacique Ygnacio Lebihueque del Butalmapu de la Cordillera quien indica como causa del levantamiento la conducta de

[...] quatro españoles que lo fueron Don Salvador Cabrito, siendo Maestre de Campo General de esta frontera, Juan Rey Comisario de Naciones, Martin Soto Lengua General, y del Capitan de Amigo Carlos Garzes que todos juntos concurrieron a violentarlos para la formación de Pueblos (Parlamento de Negrete, 1771, p. 289).

Narración que se volvió a oír en el Parlamento de Santiago de 1772, en que se señala por el mismo Lebihueque que fue el maestre de Campo General Salvador Cabrito quien levantó la tierra por apresar al cacique Curiñancu:

[...] haverlos querido precisar a ponerlos a pueblos en sus mismas tierras de cuyos insultos recibieron el agravio de pegarles fuego sus casas, como asi mismo de haver sido el principal Instrumento, para hallarse oy dia todos pereciendo de necesidades con pérdidas de todas sus Haciendas, Manteniendose con yerbas de el Campo, y con los Perros de sus casas, estos son los agravios que manifiestan (Parlamento de Santiago, 1772, p. 301).

En el Parlamento de Tapihue de 1774 varios "caciques gobernadores" precisaron que el cumplimiento de las capitulaciones presentadas por el Capitán General, no comprendía la fundación de pueblos

[...] porque todos comprehendian que estos no les era útiles, y no les parecía conveniente condecender a su establecimiento; $y$ haviendoseles respondido que de ninguna suerte se parava en tal fundacion, que el Rey absolutamente no necesitava de [sus] tierras, ni quería mas que la quietud, y comveniencia de ellos, y [que] le fuese fieles Basallos (Parlamento de Tapihue, 1774, p. 327).

En dicho Parlamento de 1774 se capituló que se nombrarán "Alcaldes o jueces de sus reducciones [...] recaiendo los nombramientos en indios nobles: de los de mejor opinion capacidad y juicio" (Parlamento de Tapihue, 1774, p. 321) y que fuera de cargo de la Corona la educación de los hijos de los caciques en la escuela fundada para esos efectos. 
En 1784 en el Parlamento de Lonquilmo se acordó la celebración de cuatro ferias en los meses de octubre, noviembre, febrero y abril. Y se reconoció la colaboración indígena, en particular las parcialidades de Arauco, en la guerra contra los ingleses ("Moro-guincas") (Parlamento de Lonquilmo, 1784).

La preocupación respecto de la presencia inglesa en el sur de Chile estaba absolutamente fundada, como demuestra María Urbina a propósito de la fallida fortificación de Chiloé:

La coyuntura de 1749 puso en el mapa imperial a una isla del archipiélago de los Chonos porque ponía en riesgo las riquezas del virreinato de Lima, que era lo que en definitiva se quería resguardar. La Patagonia Occidental pasó a ser un territorio con significado estratégico y geopolítico desde esa coyuntura y durante la segunda mitad del siglo XVIII, a pesar de que esto no se tradujo en una ocupación española. Esta atención a Chiloé era algo inédito para una provincia pobre y lejana. Órdenes peninsulares que dispusieran una expedición a Chiloé, y que se enviara un barco de guerra con este propósito, no se habían visto desde que en 1675 -y también fue inusual-, pasara a Chiloé un navío de guerra desde Perú, bien provisto y con oficialidad de alto rango, para buscar un posible establecimiento inglés entre el golfo de Penas y el estrecho de Magallanes (Urbina, 2014).

\section{Conclusiones}

El análisis conjunto del manuscrito inédito "Manifiesto que acredita las utilidades que se conseguirán en reducir los indios chilenos a vivir en población, los medios de conseguirlo y condiciones con que se ha de practicar", y de los Parlamentos de 1593, 1726, 1738, 1764, 1771, 1772, 1774 y 1784, permite ampliar la comprensión de la propuesta de reducciones y de las causas del levantamiento de 1766: (i) si se tiene a la vista el memorial no cabe calificar la propuesta como irresponsable, o fundada en el desconocimiento de la realidad. El texto prueba que hubo una reflexión sobre la temática y que se estimó conveniente a los intereses de la Corona y de los religiosos, y en menor medida de los vecinos involucrados en el comercio con los indios; (ii) la propuesta resultaba también de interés para ciertas comunidades indígenas, en razón de las guerras internas y la precaria situación económica de algunas parcialidades. Favorecía el fortalecimiento del poder de los dirigentes (caciques o lonkos) de las parcialidades indígenas aliadas de los españoles, y ella suscitó cierto interés como se desprende del hecho que no la rechazaran de entrada; $y$ (iii) no cabe señalar como elemento determinante de la revuelta de 1766 a la "juvenil e irresponsable propuesta jesuita de reducciones", sino al errado tratamiento por parte del gobernador de la conducta negativa del cacique Curiñancu. El hecho de la prisión y la amenaza de muerte del cacique y su aliado, fue la chispa del levantamiento.

Los datos aportados por los Parlamentos de 1764, 1771, 1772, 1774 y 1784 indican que el afán de implementar la política de reducción a poblaciones implicó una amenaza concreta en 1764 a la integridad física y la libertad del lonko Curiñancu, cuestión en la que no se había reparado hasta ahora. Hecho que puede estar en la base de su accionar bélico de 1766. Ello implica reflexionar acerca del impacto de una decisión política tan severa en la eficacia de la propuesta de reducciones, y por lo mismo, ampliar la explicación acerca de su fracaso.

La propuesta jesuita debe comprenderse mediatizada por la política gubernamental que estimó el uso de la fuerza como conducente a garantizar la eficacia de la misma. Los hechos posteriores mostraron que el arresto y amenaza a la integridad física y la libertad de Curiñancu terminó favoreciendo la causa indígena, sin que ello impidiera a la vez implementar alguna de las propuestas que se tuvieron a la vista a propósito de la justificación de la política de reducciones.

Cabe considerar también, que las fuentes históricas empleadas aportan antecedentes para 
enriquecer la explicación de la Escuela Chilena de Historia del Derecho respecto de los pueblos de indios y el caso particular de los indios rebeldes del Reino de Chile.

\section{Referencias}

Adán, L., Mera, R., Navarro, X., Campbell, R., Quiroz, D. \& Sánchez, M. (2016). Historia prehispánica en la región Centro-sur de Chile: cazadores-recolectores holocénicos y comunidades alfareras (10.000 años a. C. a 1.550 años d. C). En: F. Falabella, M. Uribe, L. Sanhueza, C. Aldunate \& J. Hidalgo (eds.). Prehistoria en Chile. Desde sus primeros habitantes hasta los Incas (pp. 401-442). Santiago de Chile: Editorial Universitaria / Sociedad Chilena de Arqueología.

Alcamán, E. (1997). Los mapuche-huilliche del futahuillimapu septentrional: guerra colonial, guerras internas y alianzas políticas (1750-1792). Revista de Historia Indígena, 2, 29-75.

Bonilla, T. (1988). La "gran guerra" mapuche 1541-1883. Análisis crítico histórico. Historia militar de Araucanía. Santiago de Chile: Instituto Geográfico Militar.

Casanova, H. (1987). Las rebeliones araucanas del siglo XVIII. Mitos y realidad. Temuco: Universidad de la Frontera, Serie Quinto Centenario.

Contreras, H. (2016). Migraciones locales y asentamiento indígena en las estancias españolas de Chile central, 1580-1650. Revista Historia, 49(I), 87-110.

Correa, M. \& Mella, E. (2009). El territorio mapuche de Malleco: las razones del Illkun. Temuco: Observatorio de Derechos de los Pueblos Indígenas. Disponible en: http://www.iwgia. org/iwgia_files_publications_files/0273_LAS_ RAZONES_DEL_INKULL.pdf

De la Sala, J. (1986). Visita General de la Concepción y su obispado por fray Pedro Ángel de Espiñeyra, su meritísimo prelado
1765-1769. Chillán: Instituto Profesional de Chillán.

De la Torre, J. (1992). El pensamiento novohispano ante el descubrimiento y la conquista, opinión de las órdenes monásticas con relación a la guerra chichimeca. Revista de Estudios Histórico-Jurídicos, 15, 265-273.

Dougnac, A. (1994). Manual de historia del derecho indiano. Ciudad de México: Universidad Nacional Autónoma de México.

Durston, A. (1999). El proceso reduccional en el sur andino: confrontación y síntesis de sistemas espaciales. Revista de Historia Indígena, 4, 75-101.

Falabella, F., Uribe, M., Sanhueza, L., Aldunate, C. \& Hidalgo, J. (eds.). (2016). Prehistoria en Chile. Desde sus primeros habitantes hasta los Incas. Santiago de Chile: Editorial Universitaria / Sociedad Chilena de Arqueología.

Ferrando, R. (1986). Y así nació La Frontera... Conquista, guerra, ocupación, pacificación 1550-1900 (2a ed.). Santiago de Chile: Editorial Antártica.

Goicovich, F. (2007). Entre la conquista y la consolidación fronteriza: dispositivos de poder hispánico en los bosques meridionales del reino de Chile durante la etapa de transición (1598-1683). Revista Historia, 40(II), 311-332.

Gussinyer i Alfonso, J. (1994). Congregación indígena y pueblos de indios en las Antillas, 1500-1525. Boletín Americanista, 44, 73-109.

Jara, A. \& Pinto, S. (1981). Fuentes para la historia del trabajo en el Reino de Chile. Legislación. Tercera parte. Continuación. Revista Chilena de Historia del Derecho, 8, 131-210.

León, L. (1990). El malón de Curiñamcu. El surgimiento de un cacique araucano (17641767). Proposiciones, 19, 18-43.

León, L. (1995). Conflictos de poder y guerras tribales en Araucanía y las pampas: la 
batalla de Tromen (1774). Revista Historia, 29, 185-233.

Levaggi, A. (2001). República de indios y república de españoles en los Reinos de Indias. Revista de Estudios Histórico-Jurídicos, XXIII, 419-428.

Lorenzo, S. (2004). Fuentes para la historia urbana en el Reino de Chile. Régimen legal de la fundación de ciudades en Chile durante el siglo XVIII. Santiago de Chile: Academia Chilena de la Historia.

Ocaña, D. (1995). Viaje a Chile: relación del viaje a Chile, año de 1600, contenida en la crónica de viaje intitulada "A través de la América del Sur". Santiago de Chile: Editorial Universitaria.

Pereira, E. (1995). Relación del viaje de fray Diego de Ocaña por el Nuevo Mundo 1599-1605. Santiago de Chile: Editorial Universitaria.

Rosati, H. (1995). El imperio español y sus fronteras: mapuches y chichimecas en la segunda mitad del siglo XVI. Revista Historia, 29, 591-404.

Solano, F. (1990). Ciudades hispanoamericanas $y$ pueblos de indios. Madrid: Consejo Superior de Investigaciones Científicas.

Suriz, P. (2011). Disputas a orillas del río Uruguay. Guerra y paz con los minuanes en el siglo XVIII. Gazeta de Antropología, 27(2). Disponible en: http://www.ugr.es/ pwlac/ G27_37PedroMiguelOmar_Svriz_Wucherer.html

Szászdi, I. \& Palma, E. (1998). El parlamento hispano-araucano de 1641: naturaleza jurídica de un pacto internacional. En: G. Pinard \& A. Merchán (eds.). Libro homenaje in memoriam Carlos Díaz Rementería (pp. 699-711). Huelva: Universidad de Huelva.

Urbina, M. (2014). El frustrado fuerte de Tenquehuen en el archipiélago de los chonos, 1750: dimensión chilota de un conflicto hispano-británico. Revista Historia, 47(I), 133-155.

Vega, A. (1999). Asentamiento y territorialidad indígena en el partido del Maule en el siglo XVI. Revista Historia, 32, 685-708.

Villalobos, S. (1995). Vida fronteriza en la Araucanía. El mito de la guerra de Arauco. Santiago de Chile: Andrés Bello.

Whipple, P. (1998). Encomienda e indios de estancia durante la segunda mitad del siglo XVII. Melipilla 1660-1681. Revista Historia, 31, 349-382.

Zavala, J. (2011). Los mapuches del siglo XVIII. Dinámica interétnica y estrategias de resistencia. Temuco: Universidad Católica de Temuco.

Zavala, J. (ed.). (2015). Los parlamentos hispanomapuches, 1593-1803: textos fundamentales. Temuco: Universidad Católica de Temuco.

Zavala, J. \& Dillehay, T. (2010). El "Estado de Arauco" frente a la conquista española: estructuración sociopolítica y ritual de los araucano-mapuches en los valles nahuelbutanos durante los siglos XVI y XVII. Chungará, Revista de Antropología Chilena, 42(2), 433-450. 